American Journal of Applied Sciences 5 (7): 798-804, 2008

ISSN 1546-9239

(C) 2008 Science Publications

\title{
Assessment of Suspended Sediments Concentration in Surface Waters, Using Modis Images
}

\author{
Mobasheri Mohammad Reza \\ Department of Remote Sensing Engineering, K. N. Toosi University of Technology, \\ P.O.Box 15875-4416 Tehran, Iran
}

\begin{abstract}
Remote sensing from air-borne and space-borne sensors have proved to be a useful method for Suspended Sediment Concentration (SSC) estimation as it provides an instantaneous and synoptic view of suspended sediments that would otherwise be unavailable. The reason for the success of remote sensing in such surveys is the strong positive relationship that exists between SSC and remotely sensed water leaving radiance. To find an algorithm relating SSC to spectral radiance over Bahmansheer River Estuary at the North-West of Persian Gulf, a three-month field expedition (April to June 2003) was conducted while the MODIS sensor on board Terra simultaneously flew over the scene. Fifty seven samples in fifteen trips were collected. The collected samples were analyzed by measuring concentration, diameters of the sediment particles and by determining the sediment constituents. Total concentration ranged between 30 and $500 \mathrm{mg}$, the range of particle diameter was from less than a micrometer to more than 20 micrometers and finally it was found that the sediment was composed of Quartz, Kaolinite, Orthoclase, Chlorite, Calcite, Gypsum, Muscovite, Halite, Anhydrite, Apatite, Biotite and a low amount of Albite. It is found that the spectral characteristics of these compositions are partly responsible for the reflected and/or scattered energy in different bands while the correlation between larger suspended particle concentration and spectral radiance was profound.
\end{abstract}

Key words: Remote sensing, suspended sediment concentration algorithm, estuary, MODIS

\section{INTRODUCTION}

Since the late 1970's remote sensing studies of suspended sediments have been made using the fact that suspended sediments increase the radiance emergent from surface waters in the visible and near infrared region of the electromagnetic spectrum ${ }^{[1]}$. Most researches that had a large range (i.e., $0-200+\mathrm{mg} \mathrm{L}^{-1}$ ) of suspended sediment concentration have found a curvilinear relationship between suspended sediments and radiance or reflectance ${ }^{[2,3,4]}$. This is because the amount of reflected radiance tends to saturate the respected channels used for detection as suspended sediment concentrations increase. The point of saturation is wavelength dependent, with the shorter wavelength channels saturating at lower concentrations.

If SSC is less than $50 \mathrm{mg} \mathrm{L}^{-1}$, then reflectance in almost any wavelength band will be significantly related to suspended sediment concentrations (Ritchie and Schiebe 2000). As the range of SSC increases to $200 \mathrm{mg} \mathrm{L}^{-1}$ or higher, curvilinear relationships have to be developed for reflectance in the longer wavelength. Relationships have been discovered that relate suspended sediments and radiance or reflectance retrieved from individual satellite spectral bands and from spectral bands combinations. ${ }^{[1]}$ used in situ studies concluded that wavelengths between 700 and $800 \mathrm{~nm}$ were most useful for determining suspended sediments in surface waters. Many studies have developed algorithms for the relationship between the concentration of suspended sediments and radiance or reflectance $^{[5]}$. A few studies have taken the next step and used these algorithms to estimate suspended sediments for another time or place ${ }^{[6]}$.

Variations of sediment type (grain size and refractive index) and changing illumination conditions affect the reflectance signal of coastal waters and limit the accuracy of sediment-concentration estimations from remote-sensing measurements ${ }^{[7]}$. Table 1 shows a list of algorithm for derivation of SSC from satellite images using different spectral bands ${ }^{[5]}$. These algorithms may work for the conditions where they have been derived for. These conditions involve satellite sensor, range of SSC, type and characteristics of sediments or suspended matters, physics of the environment and many more factors. Applying these algorithms in different regions and to some other sensors products may not necessarily work at least due to the difference in the sensor's spectral bands.

The six out of seven MODIS/Terra channels shown in Table 2, centered at 0.55, 0.66, 0.86, 1.24, 1.64 and $2.13 \mu \mathrm{m}$, are commonly being used with aerosol 
Am. J. Applied Sci., 5 (7): 798-804, 2008

Table 1: A list of algorithms for derivation of SSC using radiances in different spectral bands $a, b, c$ and $d$ are constants and $L_{\lambda}$ is radiance in band centered at $\lambda$ (Mobasheri $\left.{ }^{5}, 2003\right)$

\begin{tabular}{llllll}
\hline $\begin{array}{l}\text { Correl. } \\
\text { Coeffi. }\end{array}$ & Error mg/L & $\begin{array}{l}\text { Sampling } \\
\text { location }\end{array}$ & O. of samples & $\begin{array}{l}\text { Range of } \\
\text { SSC mg/L }\end{array}$ & $\begin{array}{l}\text { Relation between } \\
\text { SSC and } \mathrm{L}_{\lambda}\end{array}$ \\
\hline 0.60 & 0.46 & Channel & 29 & $21-2$ & $\log (\mathrm{SSC})=\mathrm{a}+\mathrm{b} \mathrm{L}_{\lambda 1}+\mathrm{cL}_{\lambda 2}+\mathrm{d} \mathrm{L}_{\lambda 3}+\mathrm{e} \mathrm{L}_{\lambda 4}$ \\
0.90 & unknown & Unknown & 72 & $70-2$ & $\mathrm{SSC}=\mathrm{a}+\mathrm{b} \log \left(\mathrm{L}_{\lambda 1}\right)+\mathrm{c} \log \left(\mathrm{L}_{\lambda 2}\right)$ \\
0.83 & unknown & Black sea & 8 & $15-2$ & $\operatorname{Log~SSC}=\mathrm{a}+\mathrm{b}\left(\mathrm{L}_{\lambda 1}-\mathrm{L}_{\lambda 2}\right)\left(\mathrm{L}_{\lambda 3} / \mathrm{L}_{\lambda 1}\right)$ \\
0.60 & unknown & Coastal waters & 23 & $200-5$ & $\operatorname{Log~SSC}=\mathrm{a}+\mathrm{b} \mathrm{L}_{\lambda 1}+\mathrm{cL}_{\lambda 2}$ \\
0.89 & unknown & Channel & 31 & $21-2$ & $\operatorname{Log~SSC}=\mathrm{a}+\mathrm{b} \mathrm{L}_{\lambda 1}+\mathrm{cL}_{\lambda 2}+\mathrm{dL}_{\lambda 3}$ \\
0.96 & 4.11 & Bay & unknown & $32-1$ & $\mathrm{SSC}=\mathrm{a}+\mathrm{b} \mathrm{L}_{\lambda 1}+\mathrm{cL}_{\lambda 2}$ \\
\hline
\end{tabular}

Table 2: First 7 channels of MODIS/Terra

\begin{tabular}{lll}
\hline Channel No. & Spectral Range $(\mu \mathrm{m})$ & $\begin{array}{l}\text { Channel } \\
\text { Center }(\mu \mathrm{m})\end{array}$ \\
\hline 1 & $0.620-0.670$ & 0.66 \\
2 & $0.841-0.876$ & 0.86 \\
3 & $0.459-0.479$ & 0.47 \\
4 & $0.545-0.565$ & 0.55 \\
5 & $1.230-1.250$ & 1.24 \\
6 & $1.628-1.652$ & 1.64 \\
7 & $2.105-2.155$ & 2.13 \\
\hline
\end{tabular}

retrieving algorithms, deriving aerosol models and aerosol optical depths. Due to the strong scattering in channel 3 by the atmosphere and strong absorption in channels 5, 6 and 7, by the water mass, then the water leaving radiance is assumed to be zero in these channels. This means that it remains the effects of the atmosphere on these channels where we assumed that in a clear and homogeneous atmosphere these effects will not alter from pixel to pixel. The reflectance of channel 1 and 4 was assumed to be the typical of clear water (case 1 water) reflectance. In a clear atmosphere, any unaccounted elevated values in the water leaving radiance in these two channels were interpreted as an increase in the optical thickness of the fine particles in the sediments as well as reflection from the substrate in shallow waters for low values of SSC. The effect of sea floor on the reflected radiance even in the shorter region of the spectrum is minimal when SSC is high enough. This unaccounted radiance may results in systematic overestimation of the atmospheric aerosol optical thickness.

It is believed that the main differences between the two types of waters (clear and turbid) are located in the 0.4-0.7 $\mu \mathrm{m}$ spectral range ${ }^{[8]}$ where the turbid water has significantly larger reflectance than the clear water. This formed the basis for the detection of turbid water and SSC estimation algorithms. The penetration depths in clear water at the level of $90 \%$ light attenuation is as high as 40 meters for channel 3 and as low as a millimeter for channel $7^{[9]}$. Thus, the turbidity in water can affect reflectance in the visible channels and even at $0.86 \mu \mathrm{m}$. This means that the higher values of SSC may limit the depth of penetration of band 4 to a few centimeters and increase the amount of scattering in this band as a consequence. This was the case in our work where the estuary was so turbid that the secchi disk value was less than 40 centimeters.

Due to the small penetration depths of sunlight into the water for the longer wavelengths $(1.24,1.64$ and $2.13 \mu \mathrm{m})$, the possibility of the reflection by sea floor substrate is negligible. On the other hand, the blue channel $(0.47 \mu \mathrm{m})$ is very sensitive to atmospheric molecular scattering, but less sensitive to the additional reflection by sediments ${ }^{[8]}$.

The sensitivity of this channel to sea floor sediment reflection for coastal clear waters, is not nearly as great as the $0.55 \mu \mathrm{m}$ channel. This is because of strong absorption by dissolved organic matters (yellow substances) at $0.47 \mu \mathrm{m}$.

In summary, the MODIS measurements over the ocean at $0.47,1.24,1.64$ and $2.13 \mu \mathrm{m}$ are influenced mainly by aerosol scattering and absorption and can be used to derive the atmospheric spectral power $\operatorname{law}^{[8]}$. Measurements at 0.55-0.86 $\mu \mathrm{m}$ are influenced both by the aerosol and the sediments. The excess reflectance at 0.55 and $0.86 \mu \mathrm{m}$ above the power law values can be associated to the presence of suspended sediments in the turbid water (where the visibility of secchi disk is low) and consequently is used for their detection in this work.

\section{MATERIALS AND METHODS}

Bahmansheer River is situated at the southwest of Iran and is $80 \mathrm{~km}$ long parallel to Arvand River, which is the border of Iran and Iraq (Fig. 1). This river carries large amounts of sediments to the Persian Gulf (which varies with the tide). The tidal current influences the water level even at the junction of this river with the Arvand River some $80 \mathrm{~km}$ far from its estuary.

These tidal currents usually keep the water at the estuary turbid for the most of the time. This turbidity may extend to few kilometers from the estuary to further upstream the river, where heavier particles sink to the sea floor and will not return to the estuary even by tidal currents.

We have collected our samples in the vicinity of the estuary (Fig. 1), while MODIS sensor onboard of 
Am. J. Applied Sci., 5 (7): 798-804, 2008

Table 3: Sediment constituents, with chemical name and formula [10]

\begin{tabular}{|c|c|c|c|}
\hline Name & Formula & $\begin{array}{l}\text { Presence in Nature and/or } \\
\text { Industry }\end{array}$ & Interaction with light \\
\hline Albite & NaAlSi3 O8 & $\begin{array}{l}\text { Ornamental stone, ceramics and } \\
\text { Mineral specimens }\end{array}$ & Translucent to Transparent \\
\hline Anhydrite & $\mathrm{CaSO} 4$ & $\begin{array}{l}\text { In the manufacture of } \\
\text { some cement }\end{array}$ & Transparent to Translucent \\
\hline Apatite & $\begin{array}{l}\mathrm{Ca} 5(\mathrm{PO} 4) \\
3(\mathrm{OH}, \mathrm{F}, \mathrm{Cl})\end{array}$ & $\begin{array}{l}\text { As a source of phosphorous tobe } \\
\text { used in fertilizer }\end{array}$ & Transparent to Translucent \\
\hline Biotite & $\begin{array}{l}\mathrm{K}(\mathrm{FE}, \mathrm{Mg}) 3 \mathrm{AlSi} 3 \\
\mathrm{O} 10(\mathrm{~F}, \mathrm{OH}) 2\end{array}$ & $\begin{array}{l}\text { Heat insulator for industrial } \\
\text { purposes }\end{array}$ & Transparent to Translucent \\
\hline Calcite & $\mathrm{CaCO} 3$ & $\begin{array}{l}\text { In cements and mortars, production } \\
\text { of lime and some other industries }\end{array}$ & Transparent to Translucent \\
\hline Chlorite & $\begin{array}{l}(\mathrm{Fe}, \mathrm{Mg}, \mathrm{Al}) 6(\mathrm{Si}, \mathrm{Al}) \\
4 \mathrm{O} 10(\mathrm{OH}) 8\end{array}$ & $\begin{array}{l}\text { As a mineral specimen and some } \\
\text { industrial uses }\end{array}$ & Transparent to Translucent \\
\hline Gypsum & $\mathrm{CaSO} 4-2(\mathrm{H} 2 \mathrm{O})$ & $\begin{array}{l}\text { some cements, fertilizer, paint filler, } \\
\text { ornamental stone }\end{array}$ & Transparent to Translucent \\
\hline Halite & $\mathrm{NaCl}$ & $\begin{array}{l}\text { Major source of salt and as } \\
\text { mineral specimens }\end{array}$ & Transparent to Translucent \\
\hline Kaolinite & $\mathrm{Al}_{2} \mathrm{Si}_{2} \mathrm{O}_{5}(\mathrm{OH})_{4}$ & $\begin{array}{l}\text { In the production of ceramics and } \\
\text { some other industry uses }\end{array}$ & Translucent \\
\hline Muscovite & $\begin{array}{l}\mathrm{KAl} 2(\mathrm{AlSi} 3 \mathrm{O} 10) \\
(\mathrm{F}, \mathrm{OH}) 2\end{array}$ & $\begin{array}{l}\text { Heat and electrical insulator } \\
\text { for industrial purposes }\end{array}$ & Transparent to Translucent \\
\hline Orthoclase & KAlSi3O8 & $\begin{array}{l}\text { Mineral specimens and in the } \\
\text { porcelain industry }\end{array}$ & Opaque to Translucent \\
\hline Quartz & $\mathrm{SiO} 2$ & $\begin{array}{l}\text { Silica for glass, electrical } \\
\text { Components }\end{array}$ & Transparent for visible \\
\hline
\end{tabular}

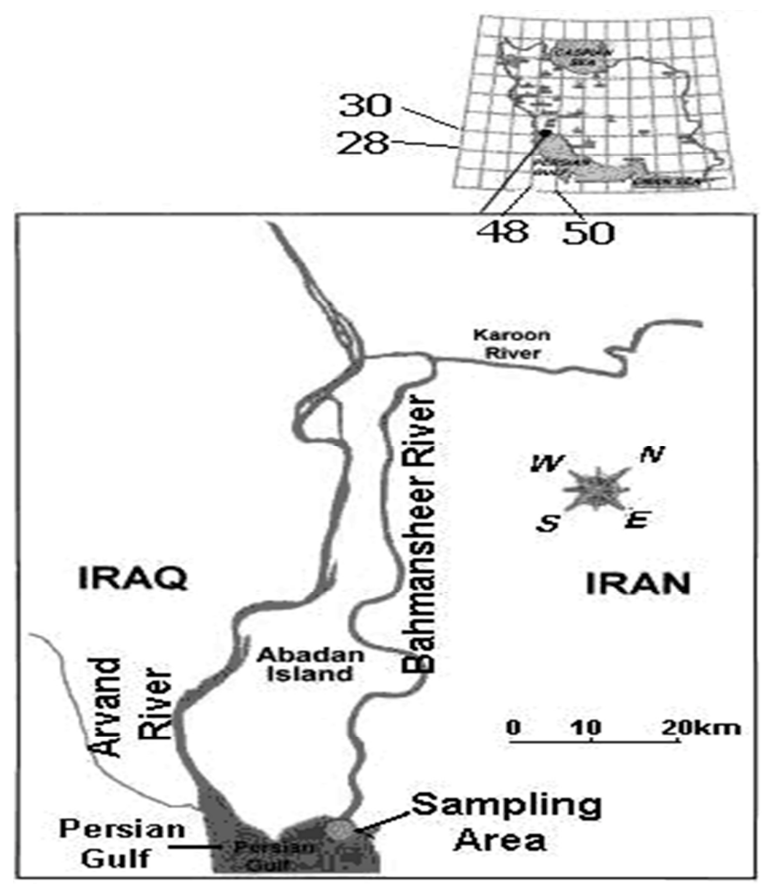

Fig. 1: Map of sampling area, northwest of Persian Gul

Terra was passing over the region. Sampling is made by collecting surface water (200 to $1000 \mathrm{ml}$ ) from the boat.

Each sample was a minimum distance of 500 meters apart. Along with the sample collection, latitude and longitude of the sample were determined (using a
GPS set). Also parameters like current speed and direction profile (for determination of tidal state), water temperature, wind speed and direction (in the nearest meteorological station) and atmospheric visibility were collected. These data were used for quality assessment of the images.

Then the collected samples were taken to the laboratory for measurement of concentration, particle size distribution (using Mastersizer) and composition analysis (using X-Ray Diffracto-meter). The concentrations of the collected samples were as low as 30 and as high as $500 \mathrm{mg} \mathrm{L}^{-1}$. Due to the well mixing of the suspended sediments while running in the river, proportion of each of constituents in the composition for all collected samples was found to be relatively the same. Only the particle size distribution was different from point to point. Because, only 1 to $15 \%$ of the particles had diameters of less than $1 \mu \mathrm{m}$, the majority of the particles were too large to perform Rayleigh scattering. On the other hand diameter of more than $45 \%$ of the particles was between 0.1 and 9 micrometer. These particles may undergo Mie scattering in the channels 1, 2, 3 and 4 of MODIS. The rest of particles may have nonselective scattering. As a result, the assumption of a Lambertian reflection for the region under low wind speed conditions (absence of sun glitter) and high SSC, is reasonable. Of course those pixels where the light is specularly reflected to the sensor (sun glint) are excluded.

It was found that at low tide (Flood), the surface particle size distribution was higher and the turbidity was increased. This increase in turbidity was the main 


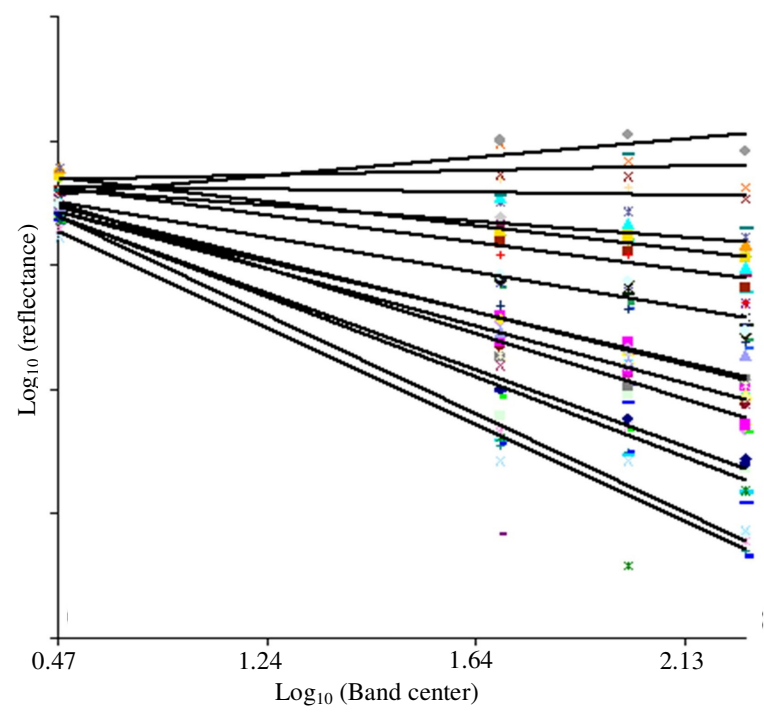

Fig. 2a: Reflectance in channels 3, 5, 6 and 7 with respect to channel's center on a log-log scale. Line fits to few samples are shown as illustration

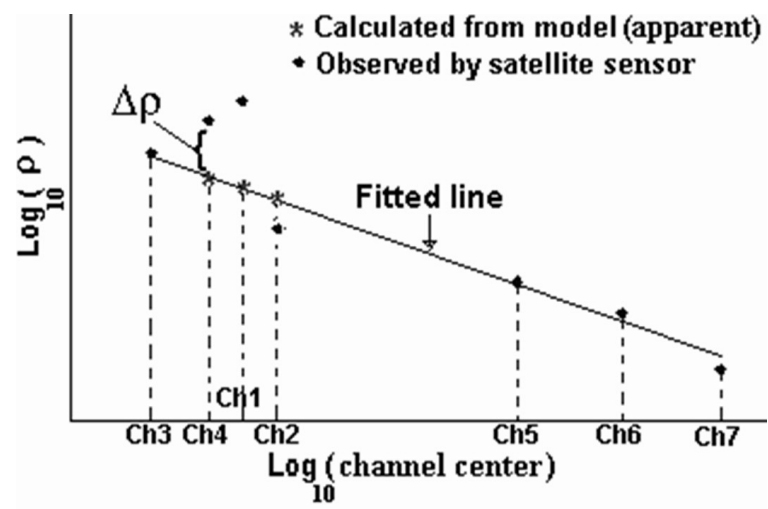

Fig. 2b: A sample calculation of apparent reflectance in channel 4, 1 and 2 using a line fitted through channels 3, 5, 6 and 7 with respect to channel's center on a log-log scale. $\Delta \rho$ is the difference between observed and apparent values of reflectance in each channel.

reason for the increase in reflections (scattering) in channels 1, 2 and 4.

Table (3) shows compositions content detected in sediment samples. As it shows almost all sediment constituents are translucent to the visible and near infrared portion of the sun spectrum. This translucency may partly be responsible for the Lambertian reflection of the turbid regions. Most of these compositions may be found in building materials and/or minerals.
The acquired images were geo-rectified using a digital map on the scale of 1:50000. Also the images were masked for cloud and dust and the contaminated pixels were omitted. Then only corrections for sun glint were implemented and no other atmospheric correction were done since the effects of atmosphere+ water should be considered ${ }^{[8]}$. The next step was converting the DN values to reflectance using the MODIS appropriate conversion equation. Using samples latitude and longitude, the relevant pixel was located and the physical values were extracted.

The plot of the spectral reflectance in channels 3, 5, 6 and 7 with respect to the channel's center on a log-log scale is shown in Fig. 2a. Except for a few samples, the reflectance values can be fitted with a straight line with a correlation of more than 0.95 . This means that the suspended sediments have not affected these channels as suggested by ${ }^{[8]}$. Those pixels whose reflectance values are not on a straight line in Fig. 2a, may have undetectable noises. The calculated correlation coefficients of the lines fitted to the data of Fig. $2 \mathrm{a}$ is shown in Fig. 3.

On the other hand for those pixels free of suspended sediment, the remaining three channels of 1 , 2 and 4 should also be fitted on this straight line namely the observed reflectance in all seven channels should lay on the same straight line on a log-log scale as is illustrated in Fig. 2 b.

Using these lines, we calculated the apparent values for reflectance in channels 1, 2 and 4 .

Due to the presence of suspended sediment at the surface, the observed reflectance by satellite sensors are usually bigger the apparent reflectance values (calculated values). This has been shown in Fig. 2b for the first sample in the first expedition.

\section{RESULTS AND DISCUSSION}

Figure 4 shows spectral reflectance curves of the sediment's compositions, where the center bands of the first seven MODIS channels are also shown in the Fig. For three channels 1, 2 and 4 that are used for SSC determination, eight of the compositions have a reflectance more than 0.80. Higher sediment concentration at the surface may contains bigger proportion of the composition with high reflectance and consequently had more influence on channel's output.

Although this graph is for pure constituents that compose a small proportion of each sample, they may affect the resultant reflectance proportional to their relative concentration in the sample. Then the effects of these constituents on the reflectance for the higher surface concentration values are more profound. For the lower surface concentrations, the effect of water 


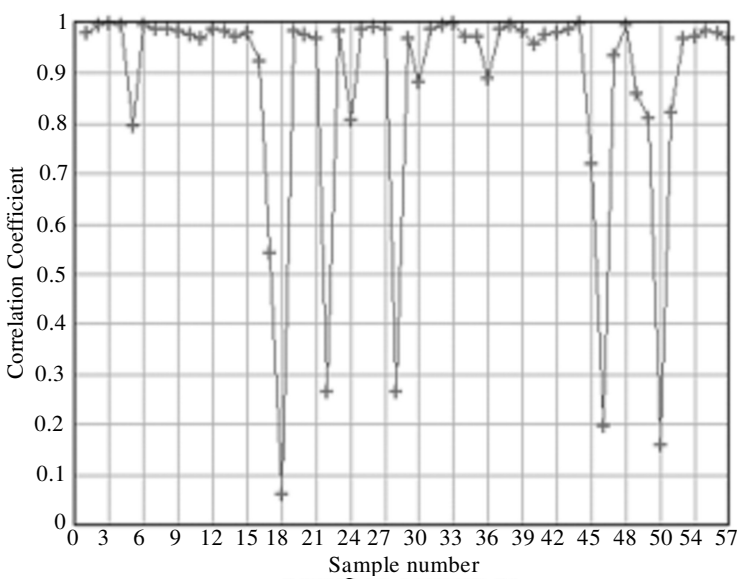

Fig. 3: The calculated correlation coefficients of the lines fitted to the data of Fig. 2-a

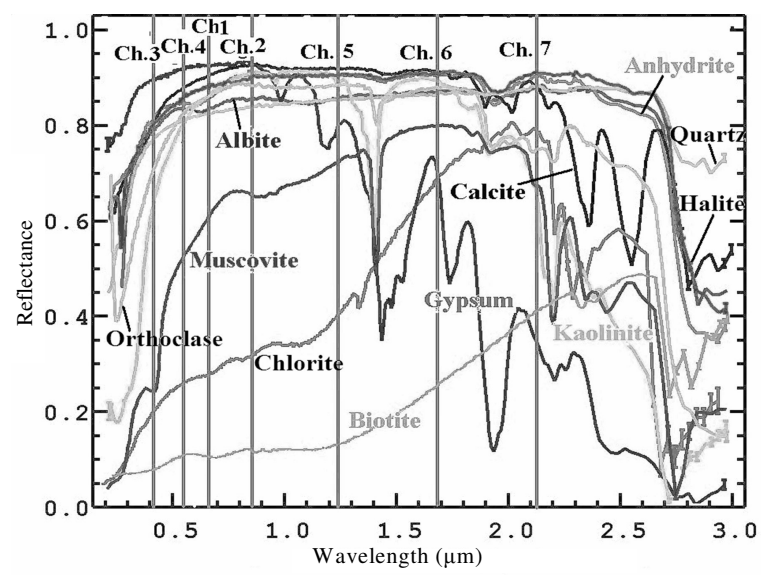

Fig. 4: Reflectance curves of the sediment's constituents [10]

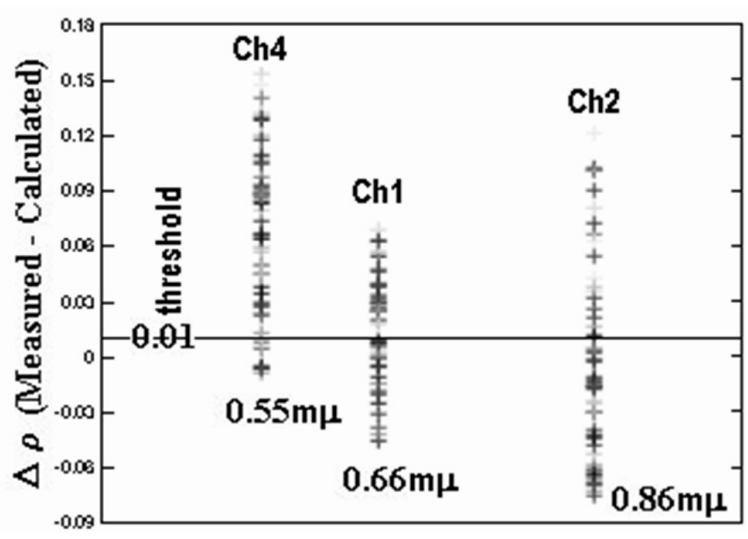

Fig. 5: Reflectance difference between calculated by the Li, et al., 2003 method and measured by the MODIS channels 1, 2 and 4

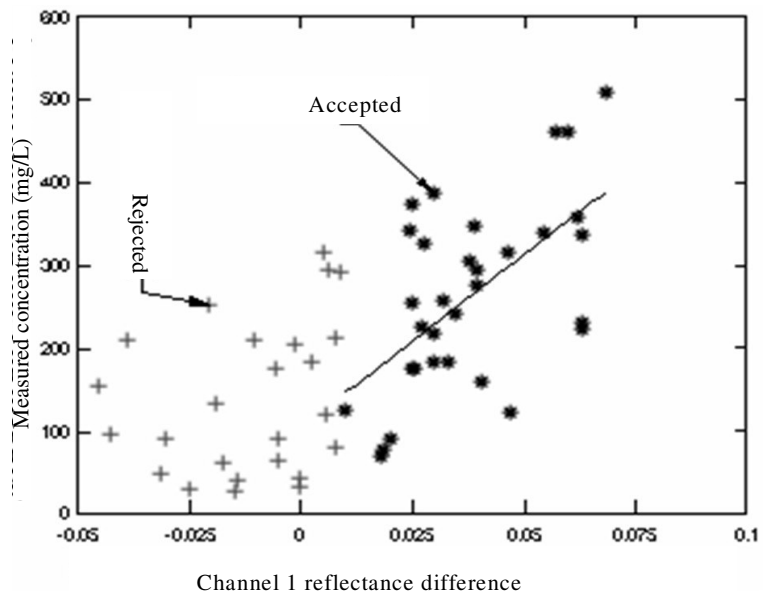

Fig. 6: Measured concentration versus reflectance difference in channell of MODIS sensor

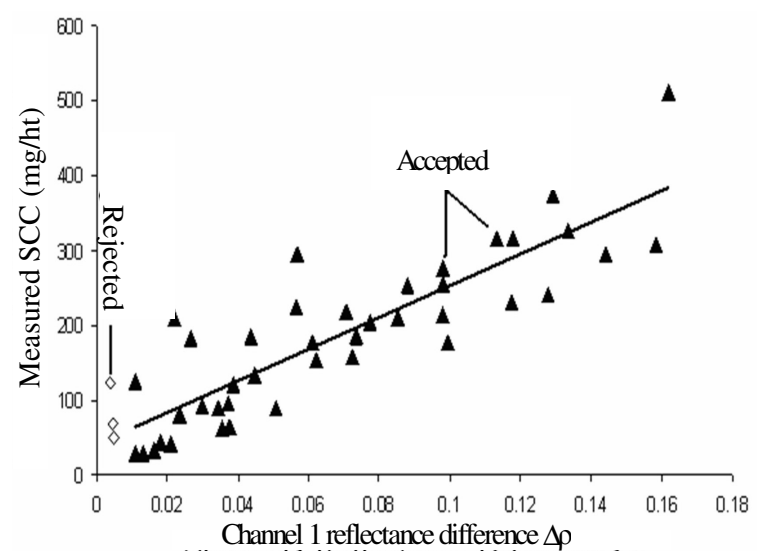

Fig. 7: Measured concentration versus reflectance difference in channel 4 of MODIS sensor

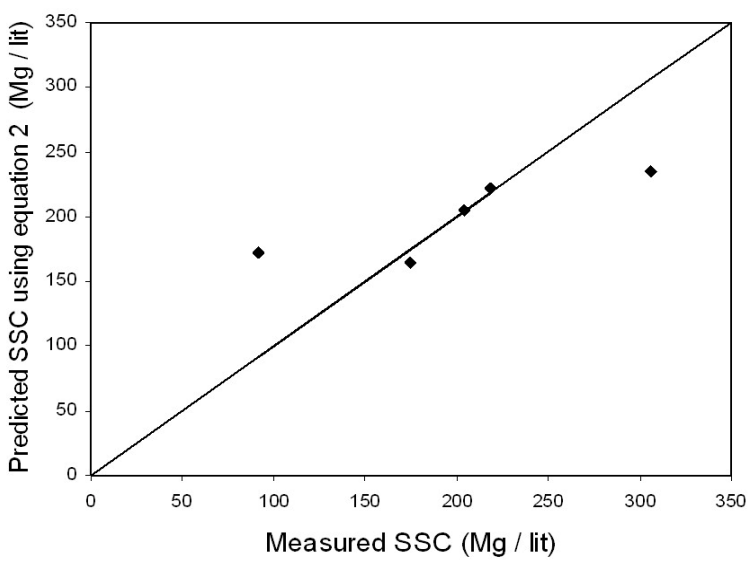

Fig. 8: Predicted SSC (using equation 2) versus measured SSC 
property on the reflectance (small reflectance in visible and strong absorption in NIR) has the leading role with a decrease in reflectance as a consequence.

As shown in Fig. 4, in channels 5, 6 and 7, the composition's reflectance decreases gradually but is not negligible when the surface sample concentration is high. This produced some difficulties in the deployment of ${ }^{[8]}$ method, especially for channels 5 and 6 and 7, due to this fact that the strong absorption by water, was much less affected by the sediment. This means that four channels 3, 5, 6 and 7 did not fit a straight line in all cases, as presumed by ${ }^{[8]}$ (Fig. 2, 3).

The linear fit to these channels reflectance (on a $\log -\log$ scale) had a correlation coefficients ranging as low as 0.15 for higher concentrations and as high as 0.999 for lower concentration values.

Figure 5 shows the difference between observed (extracted from satellite images) and calculated (apparent) reflectance for all samples. As can be seen, in some instances, the observed values of reflectance are less than calculated one (apparent) and so the difference is negative. It seems that channel 4 has the least negative values while channel 2 has the most number of negative values.

This could be due to the stronger absorption of water at channel 2 spectral band compared to the other two channels. Channel 1 has more negative values compared to channel 4 and less negative values compared to channel 2.

It is believed that the reason for negative values is the poor spatial resolution of the MODIS and strong horizontal variation in SSC so that we can hardly compare the in-situ sample with the pixel reflectance.

It was found that the negative values of $\Delta \rho$ are for higher suspended sediment concentrations. Channel 4 (centered at $0.55 \mu \mathrm{m}$ ) has less negative values, which means it has better correlation with concentrations of different values. Channel $2(0.86 \mu \mathrm{m})$ has the worst correlations with the higher values of concentrations as it has highest negative values of $\Delta \rho$.

Figure 6 shows measured concentrations versus channel 1 reflectance difference, where "+" points are below the threshold $(\Delta \rho=0.01)$ suggested by ${ }^{[8]}$.

A linear fit to the accepted data produces a poor value of correlation coefficient of 0.59 . The fitted line has the equation of the form:

Concentration $\left(\mathrm{mg} \mathrm{L}^{-1}\right)=\mathrm{a}\left(\Delta \rho_{\mathrm{ch} 1}-0.01\right)+\mathrm{b}$

where a is equal to $4160 \mathrm{mg} \mathrm{L}^{-1}$, b is $106 \mathrm{mg} \mathrm{L}^{-1}$ and $\Delta \rho_{\text {ch1 } 1}$ is dimensionless reflectance difference in channel 1 .
Figure 7 shows the same episode but for channel 4 reflectance differences. As expected, a better correlation of 0.77 between in-situ measured concentration and reflectance difference $\left(\Delta \rho_{\mathrm{ch} 4}>0.01\right)$ in this channel was found. The algorithm for channel 4 data is of the form

Concentration $\left(\mathrm{mg} \mathrm{L}^{-1}\right)=\mathrm{c}\left(\Delta \rho_{\mathrm{ch} 4}-0.01\right)+\mathrm{d}$

with $\mathrm{c}=2124.3 \mathrm{mg} \mathrm{L}^{-1}$ and $\mathrm{d}=39.8 \mathrm{mg} \mathrm{L}^{-1}$.

Algorithm 2 shows more sensitivity in detection of surface suspended sediment of coastal turbid waters than algorithm 1. Larger sediment particle concentration did not show a well-defined correlation with the total sediment concentration.

At the flood tide, more than $95 \%$ of the sediment particles had diameters above 1 micrometer, where in the ebb tide, less than $75 \%$ of particles had diameter of $1 \mu \mathrm{m}$ and above. This shows that the heavier particles have settled in the ebb situation. The correlation between channel 4 reflectance differences and concentration of sediment particles with diameter more than $1 \mu \mathrm{m}$ was about 0.81 in the flood tide.

\section{CONCLUSSION}

The effects of environmental parameters on the results were investigated. It was found that the visibility has strong influence on the correlation coefficients values. That is, higher correlation values in Fig. (3) belonged to higher atmospheric visibilities. So, it is believed that the atmospheric aerosols are the main reason for the poorness of the results. Unless we have strong mixing in the pixel area, the collected sample may hardly represent an area of minimum 25 hectares (pixel size for $500 \mathrm{~m}$ spatial resolution). This may also be a source of uncertainty in the algorithm output. This could be the case of the flood or ebb conditions at the vicinity of estuaries.

Due to low wind speed, uniformity of temperature and humidity during expeditions, no serious effects of these parameters on the results were detected. To assess the performance of equation (2), five unused samples from field expedition no. 15 were used. The result is shown in Fig. 8 with a correlation of 0.7 between predicted and measured SSCs. A line fit through the reflectance observed by MODIS channels 3, 5, 6 and 7 vs. channel's center wavelength on a log-log scale is used for calculation of channel 1 and 4 atmospheric reflectances. It is found that the difference between these atmospheric reflectance values and the observed reflectance by MODIS in the same channels (beyond a threshold value of 0.01) is proportional to total 
suspended sediment concentration, especially in high visibility conditions. Two algorithms were suggested. The first algorithm uses the reflectance difference in channel 1 and the second algorithm uses the reflectance difference in channel 4. Algorithm (2) is more sensitive to SSC variation and therefore is recommended for turbid estuaries and coastal waters.

Achieving acceptable precision is difficult because of MODIS low spatial resolution. Analysis of the algorithm sensitivity to the parameters such as grain size, chemical substances, suspended substance spectral characteristics, noises due to the spectral mixing of the suspended material, finding the best way for benefiting from algorithm (1) and (2) and many more aspects are yet to be considered.

The processing procedures involve uncertainties mostly due to the SSC spatial and temporal variability in pixels as large as 25 hectares, undetectable patches of dust in the pixel's field of view that can contaminate it, SSC dependence on the speed of river flow as well as tidal conditions and spectral mixing of the suspended material. Since we were concerned about the high values of SSCs, then the range of reflectance difference is expected to be high and as such the SSC values.

The threshold 0.01 is imposed for any reflectance difference values with the origin of either low values of SSCs (we were more interested in high values) or undetectable atmospheric effects (patches of low density of dust and/or haze in area less than a pixel size) which is common on this region.

The 0.01 threshold might not be quite suitable. This needs more analysis yet to be done. Here we just relied on the work of ${ }^{[8]}$ which might not be quite appropriate.

\section{ACKNOWLEDGMENT}

This project was funded by Khoozistan Water and Electricity Organization in Ahvaz, Iran. Also MODIS images were provided by Iran Space Agency. I hereby express my appreciation to these organizations for their supports. Also I like to appreciate Professor Ian S. F. Jones for his kind efforts in reviewing this paper. I also would like to thank Mr. H. Mousavi and Mr. Ashtari for their hard work in the field.

\section{REFERENCES}

1. Ritchie, J.C. and F.R. Schiebe, 2000. Remote Sensing in Hydrology and Water Management. Water Quality, In: G.A. Schultz and E.T. Engman (eds.) Springer-Verlag, Berlin, Germany, pp: 287-303, 351-352.

2. Ritchie, J.C., F.R. Schiebe and J.R. McHenry, 1976. Remote Sensing of Suspended Sediments in Surface Water. Photogrammetric Engineering and Remote Sensing, 42: 1539-1545.

3. Ritchie, J.C., C.M. Cooper and F.R. Schiebe, 1990. The Relationship of MSS and TM Digital Data with Suspended Sediments, Chlorophyll and Temperature in Moon Lake, Mississippi. Remote Sensing of Environment, 33: 137-148.

4. Curran, P.J. and E.M.M. Novo, 1988. The Relationship between Suspended Sediment Concentration and Remotely Sensed Spectral radiance. A Rev. J. Coastal Res., 4: 351-368.

5. Mobasheri, Mohammad Reza, 2003. Estimation of SSC by Remote Sensing Technology. Seasonal Geographical Research (in Farsi), 73.

6. Ritchie J.C. and C.M. Cooper, 1988. Comparison of Measured Suspended Sediment Concentration with Suspended Sediment Concentrations Estimated from Landsat MSS data. International Journal of Remote Sensing. 9: 379-387.

7. Doxaran David, Jean-Marie Froidefond, Patrice Castaing May 2003. Applied Optics-LP, 42: 2623-2634.

8. Rong-Rong Li, Yoram J. Kaufman, Bo-Cai Gao and Curtiss O. Davis, March 2003. Remote Sensing of Suspended Sediments and Shallow Coastal Waters, IEEE Transaction on Geoscience and Remote sensing, 41: 559.

9. Mobasheri, M. Reza, 1995. Heat Transfer in the Upper Layer of the Ocean with Application in Satellite SST Measurements. A PhD Thesis, Physics Dept., James Cook University of North Queensland, Australia.

10. Clark, N. Roger, Swayze, A. Gregg and Gallagher, 1993. Andrea J. King, Trude V.V. and Calvin, Wendy M. "US Geological Survey, Digital Spectral Library: Version $1(0.2$ to $3.0 \mu \mathrm{m})$, US Geological Survey, Open File Report 93-592. <http://www.usgs.gov/>" 